\title{
Article
}

\section{Students Investigating the Antiproliferative Effects of Synthesized Drugs on Mouse Mammary Tumor Cells}

\author{
Rasha Hammamieh, ${ }^{*}$ Margery Anderson, ${ }^{*}$ Katharine Carr, ${ }^{\dagger \S}$ Christine N. Tran,,$\S$ \\ Debra L. Yourick,* and Marti Jett*
}

*Walter Reed Army Institute of Research, Division of Pathology, 503 Robert Grant Avenue, Silver Spring, MD 20910; †Emory University, 201 Dowman Road, Atlanta, GA 30322; ${ }^{\ddagger}$ Cornell University, Department of Biomolecular and Chemical Engineering, Ithaca, NY 14850

Received October 8, 2004; Revised February 7, 2005; Accepted March 30, 2005

Monitoring Editor: William Wood

\begin{abstract}
The potential for personalized cancer management has long intrigued experienced researchers as well as the naïve student intern. Personalized cancer treatments based on a tumor's genetic profile are now feasible and can reveal both the cells' susceptibility and resistance to chemotherapeutic agents. In a weeklong laboratory investigation that mirrors current cancer research, undergraduate and advanced high school students determine the efficacy of common pharmacological agents through in vitro testing. Using mouse mammary tumor cell cultures treated with "unknown" drugs historically recommended for breast cancer treatment, students are introduced to common molecular biology techniques from in vitro cell culture to fluorescence microscopy. Student understanding is assessed through laboratory reports and the successful identification of the unknown drug. The sequence of doing the experiment, applying logic, and constructing a hypothesis gives the students time to discover the rationale behind the cellular drug resistance assay. The breast cancer experiment has been field tested during the past $5 \mathrm{yr}$ with more than 200 precollege/undergraduate interns through the Gains in the Education of Mathematics and Science program hosted by the Walter Reed Army Institute of Research.
\end{abstract}

Keywords: undergraduate, secondary, mouse tumor cells, breast cancer, personalized cancer management, genomic profiling, cellular drug resistance assay

\section{INTRODUCTION}

The Walter Reed Army Institute of Research (WRAIR) recognizes the necessity of engaging, channeling, and maintaining student participation in the quantitative disciplines. Its strong commitment to education is evidenced by the Gains in the Education of Science and Mathematics (GEMS) program that provides precollege students the opportunity to participate in laboratory research. Over the past $5 \mathrm{yr}$ almost 1,000 precollege interns have received a minimum of $40 \mathrm{~h}$ of laboratory training from WRAIR scientists. Each year, the WRAIR extends its outreach to the undergraduate population by accepting approximately 100 undergraduates as valued research assistants. To address the

DOI: $10.1187 /$ cbe.04-10-0053

Address correspondence to: Rasha Hammamieh (rasha. hammamieh@na.amedd.army.mil).

\&Undergraduate research interns. needs of this diverse student population within an active research facility while still adhering to strict deadlines and research standards, the WRAIR has developed several best practices that educate, review, and assess basic laboratory skills. These experiments are adapted from current in-house research and are interdisciplinary in that each incorporates chemistry, mathematics, biology, cell biology, and scientific writing as part of the protocol.

The breast cancer experiment was designed to be a concise, 5 -d independent project. For most undergraduates, this study becomes their first experience with a multiday experiment and its attendant accountability. In our facility, mentors have used the breast cancer assay as a rapid assessment of the undergraduate's overall abilities. For the high school student, there is the excitement of discovery and working with actual cells. The undergraduates appreciate its summation of common cell biology techniques, and the younger teens enjoy generating their own data and solving the mystery. 
The modified antiproliferative drug assay was selected as an experimental model because it is broadly applicable (Anonymous, 1999). In addition, it engages students with its robust response of dead or live cells. Student researchers use in vitro mouse mammary tumor (MMT) cultures and common chemotherapeutic drugs for the assay. Three common cancer regimens - antioxidant, anti-inflammatory, and antimitotic - are tested (Krzystyniak, 2002; Lou and Chen, 2003). Over-the-counter drugs such as aspirin are often included to demonstrate ineffectual therapies. Spectrophotometer readings provide students with an instrumental and mathematical measure of cell viability. This 5 -d immersion in cell biology experimentation delivers the excitement of discovery in a cogent framework that integrates multiple technical skills. Furthermore, it requires students to synthesize content knowledge into a single effort.

\section{BACKGROUND FOR INSTRUCTOR}

Breast cancer remains the most frequently diagnosed nonskin cancer in women. Even though 5-yr relative survival rates have been steadily increasing since 1974 from $75 \%$ to $85 \%$, breast cancer is still expected to claim 40,410 lives in the United States (National Breast Cancer Foundation, 2005; National Cancer Institute, 2005) and 1.2 million lives worldwide (Imaginis: The Breast Health Resource, 2005). An estimated 211,240 new cases of invasive breast cancer and another 58,490 new cases of in situ breast cancer will be diagnosed by the end of 2005 in the United States. These numbers remain high despite advances in our understanding of cancer's etiology, pathology, and clinical management. Fortunately, the recent emergence of genomic technologies holds therapeutic potential for personalized cancer management.

Personalized cancer management merges standard chemotherapy and radiation treatments with genomic profiling and in vitro cell proliferation studies. Individualized genomic profiling allows the researcher to identify specific genes that contribute to unregulated cellular proliferation as well as those genes that inhibit the apoptotic mechanisms that normally control cellular growth (Evan and Vousden, 2001; Lou and Chen, 2003; Radice, 2002). By determining the molecular profile of a particular cancer, rational treatment regimens can be designed that focus on those gene products that are either hyperactive or inactive in a particular tumor. A patient's genome can also reveal susceptibility to certain toxic effects of chemotherapeutic agents (Strauss, 1999).

\section{MATERIALS AND METHODS}

\section{The Laboratory Schedule}

The cellular drug resistance assay experiments are recommended for undergraduate students entering the biological sciences or allied health laboratory or for use in an advanced high school biology course. This weeklong study introduces student researchers to a relevant scientific problem and provides them with a means of solving that problem using techniques common to all laboratories. The level of difficulty is adjusted by the number of appendices/preparations that are completed by the instructor rather than the student. All experiments were conducted in laboratories at the Walter Reed Army Institute of Research.

Below are brief summaries of each day's expectations. Appendices A through $\mathrm{C}$ provide detailed instructions for instructors or advanced students. Student handouts for days 1 through 5 (Appendix D) consist of detailed protocols and questions that guide student activity and thinking. It is assumed that the instructor will maintain sufficient cultures and drug stocks and has introduced students to basic techniques and skills.

Day 1. Day 1 begins with a brief interactive discussion or review about the origin and evolution of cancer. As newly christened research assistants, the students then receive their daily outlines and are referred to the laboratory supplies table and handed a conical tube of MMT cell culture. The student/team then prepares two 96-well plates and incubates the cells overnight.

Day 2. Students confirm cell viability and confluence. All students complete a Drug Assay Worksheet (Appendix E) that is verified by the instructor. The student/team receives two samples of an unknown cancer treatment drug or combination of drugs. The completed Drug Assay Worksheet becomes the individualized protocol for that numbered drug(s). After preparing and diluting the original stock solution, students add the various concentrations of drugs to their plates. Cells are incubated with the drugs for $48 \mathrm{~h}$.

Day 3. At the beginning of day 3, the class is given an aliquot of MMT cells. Referring to a worksheet that outlines the steps of using the hemocytometer, the student learns to do a cell count and dilution. Day 3 is also a day for further discussion and beginning the report.

Day 4. In preparation for data from the spectrophotometer, the students learn to analyze sample figures, create plots, and carry out simple statistical analyses on sample data using both Microsoft Excel software and the statistical analysis features of the TI-83 graphing calculator. Cells complete the second incubation day and are placed in a freezer overnight.

Day 5. Students treat each sample well with CyQUANT lysis buffer and the fluorescent dye. The plates are scanned with a Multifluor FX scanner, and students analyze the data by taking the average intensity for each concentration of the drug used in each treatment and comparing it with the control wells. After analyzing their data, students contribute their information for group discussion and their drugs are revealed.

Assessment. For undergraduates, a written laboratory report with a level-appropriate rubric is designed by the senior scientist. Precollege students are required to submit their final plots, which are then compared with standards. Many precollege students also complete a laboratory report and/or a poster. It should be noted that the two undergraduate authors on this report began their research while in high school. The essentials of how assessment is conducted within a military facility are detailed below.

\section{Mouse Mammary Tumor Cell Culture and Maintenance}

MMT 060562 cells and all cell culture media and reagents were purchased from the American Type Culture Collection 
(ATCC; Manassas, VA). The MMT cells were maintained according to the manufacturer's instructions in Eagle's Minimal Essential medium that was modified by ATCC to contain $1.0 \mathrm{mM}$ sodium pyruvate, $0.1 \mathrm{mM}$ nonessential amino acids, and $1.5 \mathrm{~g} / \mathrm{L}$ sodium bicarbonate. The medium was supplemented with $10 \%$ fetal bovine serum and $1 \%$ PenStrep (10,000 units/mL penicillin and $100 \mu \mathrm{g} / \mathrm{mL}$ streptomycin). Cell culture flasks were maintained in a humidified $5 \%$ $\mathrm{CO}_{2}$ incubator at $37^{\circ} \mathrm{C}$. Cell viability was regularly checked with an inverted microscope. The cells were subcultured at a 1:2 ratio as needed, and media were changed every other day (Figure 1, Appendix A).

The optimal cell concentration for plating was $5 \times 10^{4}$ cells/ $\mathrm{mL}$. Cell concentration was determined with $0.4 \%$ Trypan blue solution and a hemocytometer (Appendix B). Cells were plated at $200 \mu \mathrm{L} /$ well in 96-well plates and allowed to reach $\sim 70 \%$ confluence after $24 \mathrm{~h}$. The MMT cells were then treated with varying concentrations of several therapeutic agents (or combinations of agents): curcumin, nordihydroguaiaretic acid (NDGA), tamoxifen, tamoxifen and curcumin, and tamoxifen and NDGA (Appendix C). Control and treated cells were incubated for $48 \mathrm{~h}$ at $37^{\circ} \mathrm{C}$ and $5 \% \mathrm{CO}_{2}$. (Secondary students who ask to test an over-the-counter drug or an herbal remedy can request an additional plate and develop their own dilutions/concentrations. These results become a science fair project.)

\section{Cellular Proliferation Assay}

Following a 48-h incubation period, the 96-well plates containing the drug-treated cancer cells were removed from the incubator. All media were removed, and the plates were frozen for at least $30 \mathrm{~min}$ at $-80^{\circ} \mathrm{C}$ or overnight in a $-20^{\circ} \mathrm{C}$ or $-4^{\circ} \mathrm{C}$ freezer. Students prepared reagents from the $\mathrm{Cy}$ QUANT Cell Proliferation Assay Kit (Molecular Probes, Eugene, OR) according to the manufacturer's instructions.

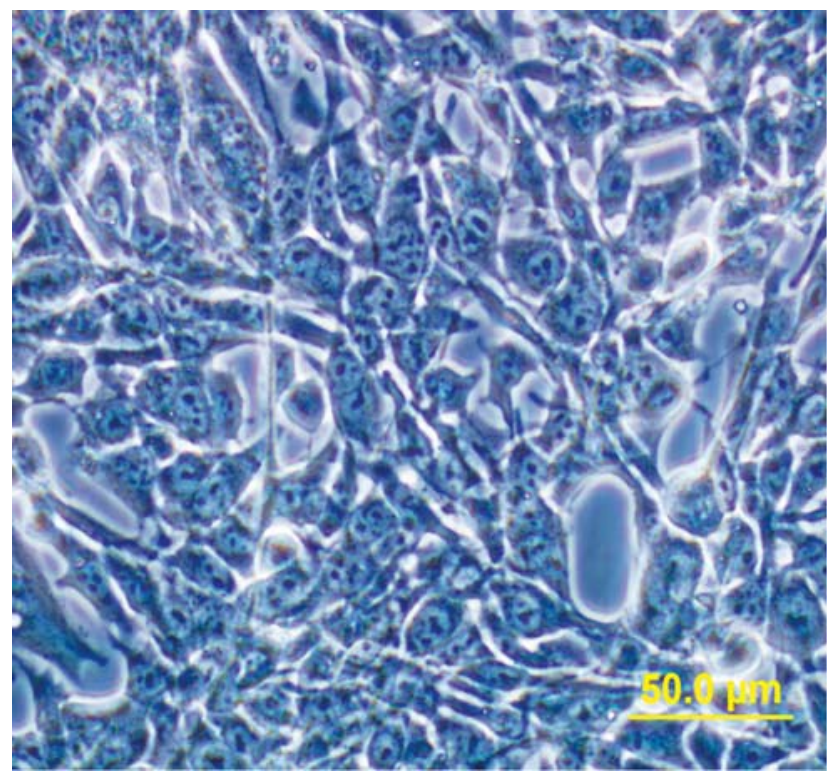

Figure 1. Photograph of MMT cells. Cells are grown to a confluent monolayer after a 24-h incubation at an initial concentration of $10^{4}$ cells/well in modified Eagle's Minimal Essential medium.
The CyQUANT kit was selected as a convenient and sensitive procedure for determining the density of cells in culture. Cells were simply thawed and lysed by addition of a buffer containing the CyQUANT GR dye to each well (Anonymous, 1999). A green fluorescent dye, CyQUANT GR exhibits stronger fluorescent characteristics upon binding to cellular nucleic acids. The degree of fluorescence is then determined by scanning the plates with BioRad's Multifluor FX scanner and analyzing the images with QuantityOne software (BioRad, Hercules, CA).

During analysis, students convert pixel values corresponding to the scanned image of each sample well to numerical values that represent the adjusted volume (cells $/ \mathrm{mm}^{2}$ ) of cells in each sample. Standard school calculators are used to give the student researchers an introduction to research mathematics beginning with basic algebra. The intern then learns/ reviews how to use a spreadsheet to analyze data exported from the scanner and how to create plots of cell density versus various concentrations of their unknown drug or combination of drugs compared with untreated controls.

\section{Antiproliferative Therapeutic Agents for Treatment of Breast Cancer}

Tamoxifen is an antimitotic drug that has been used against advanced breast cancer in postmenopausal, hormone-sensitive patients for over $20 \mathrm{yr}$ (Grandishar, 2004). For hormonesensitive neoplasms, the mix of estrogen receptor subtypes, or isoforms, is slightly modified to allow maximal estrogen binding and thus maximal stimulus for cellular proliferation. Although tamoxifen remains a successful antiestrogen therapy, recent research has revealed some serious shortcomings. First, it is now known that approximately $25 \%$ of breast cancers are not estrogen stimulated, making tamoxifen inconsequential. Second, only half of estrogen-sensitive cancers successfully respond to tamoxifen because of induced tamoxifen resistance by the enzyme protein kinase A (Chagpar, 2004). As a phytoestrogen, a traditional drug with welldocumented effects, and a well-known hormonal antagonist, tamoxifen was selected as a test drug suitable for students.

Curcumin, a yellow compound from the turmeric root, is found in various Asian and Middle Eastern herbal remedies and cuisines. Its inhibitory effect on growth has been shown to be time- and dose-dependent and is correlated with the inhibition of ornithine decarboxylase (ODC) activity (Mehta and Pantazis, 1997). Interestingly, the enzyme ODC is used to manufacture a class of proteins, polyamines, that cause cancer cells to grow more rapidly. Curcumin also exhibits a modest ability to arrest cancerous cells in the G2S phase of the cell cycle and suppress c-jun/AP-1 and NF-kappa B activation pathways, and it possesses limited anti-inflammatory activity. Patients often use curcumin as a nutritional adjuvant to standard chemotherapy (Wallace, 2002) because even limited suppression of inflammatory eicosanoids appears to decrease the growth of breast carcinomas (Krzystyniak, 2002; Teh and Hill, 2004).

NDGA, commonly found in chaparral tea, is a constituent of the creosote bush Larrea divaricata. Historically, it has been used in Native American remedies for cramping, joint pain, allergies, parasites, and cancer (McGuffin and Hobbs, 1997). As a powerful antioxidant, NDGA was investigated as a possible cancer treatment. In vitro research has shown that NDGA acts as a selective inhibitor of lipoxygenases (LOX), 
platelet-derived growth factor receptors, and protein kinase $\mathrm{C}$ intracellular signaling compounds. Each of these protein families plays an important role in the proliferation and survival of cancer. Current research has focused on finding more potent analogs of NDGA to ameliorate the high concentrations of the compound that are required for therapeutic efficacy (McDonald and Bunjobpon, 2001; Sheikh and Philen, 1997; Tong and Ding, 2002).

The activity of the antiestrogen agent, tamoxifen, was tested both individually and in combination with curcumin and NDGA. Because both curcumin and NDGA target disparate classes of proteins, it was hoped that the activity of tamoxifen would be augmented by the use of these supplementary agents. Curcumin and NDGA have historically been used as unconventional, alternative treatments for breast cancer.

\section{RESULTS}

\section{Cellular Proliferation of MMT Cells Exposed to Individual Drugs}

The three drugs chosen for our study-curcumin, NDGA, and tamoxifen-each represent unique approaches to hindering abnormal cellular proliferation (Evan and Vousden,
2001; Strauss, 1999). Although they target disparate cellular processes implicated in the deregulation of cell growth, each drug individually caused decreases in the cell population in vitro.

Of the three, tamoxifen appeared to be the most potent treatment. Figure 2 shows the culture plate for MMT cells treated with tamoxifen at increasing concentrations from left to right. Tamoxifen induced a significant inhibition in cell growth of more than $85 \%$ compared with the untreated cells (Figure 3A). These high reductions in cell proliferation show no indication of tamoxifen resistance, as would be expected in a short, 2-d incubation. In vitro conditions cannot accurately simulate in vivo estrogen availability or physiological response to prolonged tamoxifen therapy. Longer incubation periods under in vivo estrogen levels might allow time for the cells to develop the compensatory mutations and alterations in the estrogen receptor composition and pathways.

NDGA treatment resulted in the least dramatic reduction, with proliferation relative to the control populations decreased by $20 \%$ (Figure 3B). The students considered two sources of error. The students considered 1) testing more concentrated doses of NDGA or 2) increasing the length of time the cells were exposed to the less concentrated doses.

\section{A}

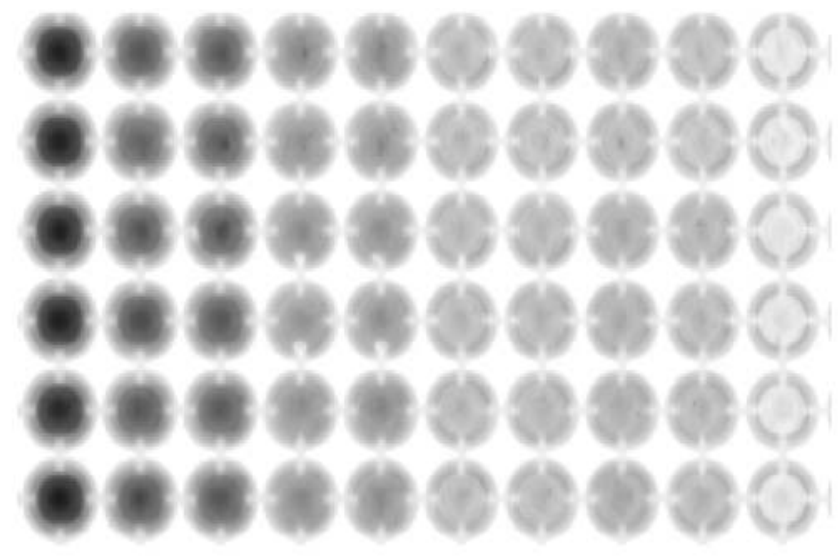

Tamoxifen: Plate 1; adiusted volume (cells $/ \mathrm{mm}^{2}$ )

\begin{tabular}{|l|c|c|c|c|c|c|c|c|c|c|}
\hline \multicolumn{10}{|c|}{ Tamoxifen: Plate 1; adiusted volume (cells/mm ${ }^{2}$ ) } \\
\hline [mM] & media & $\mathbf{0 . 0 0 5}$ & $\mathbf{0 . 0 0 5}$ & $\mathbf{0 . 0 1}$ & $\mathbf{0 . 0 1}$ & $\mathbf{0 . 0 2}$ & $\mathbf{0 . 0 2}$ & $\mathbf{0 . 0 4}$ & $\mathbf{0 . 0 4}$ & unkn \\
\hline well 1 & 20360. & 4880.7 & 7249.0 & 5948.1 & 5803.3 & 9402.3 & 2277.3 & 6537.0 & 6594.0 & 14164. \\
\hline well 2 & 21654. & 7630.7 & 11019. & 6602.4 & 4954.6 & 1960.1 & 14387. & 4495.7 & 6819.2 & 3478.2 \\
\hline well 3 & 20732. & 7038.6 & 9374.0 & 6253.2 & 4571.5 & 1490.1 & 12982. & 10472. & 6734.8 & 7791.7 \\
\hline well 4 & 18058. & 6447.7 & 6199.4 & 6258.1 & 4714.3 & 1455.9 & 11585. & 8180.1 & 7475.8 & 3778.4 \\
\hline well 5 & 18438. & 8407.9 & 8653.0 & 5184.6 & 5580.5 & 1854.3 & 8468.8 & 11409. & 1973.5 & 7561.1 \\
\hline well 6 & 17718. & 7266.2 & 5700.0 & 5306.2 & 4762.0 & 14383. & 6793.3 & 625.26 & 2206.8 & 7584.1 \\
\hline Avera & $\mathbf{1 9 4 9 3 .}$ & $\mathbf{6 9 4 5 . 3}$ & $\mathbf{8 0 3 2 . 5}$ & $\mathbf{5 9 2 5 . 4}$ & $\mathbf{5 0 6 4 . 4}$ & $\mathbf{5 0 9 1 . 0}$ & $\mathbf{9 4 1 5 . 9}$ & $\mathbf{6 9 5 3 . 3}$ & $\mathbf{5 3 0 0 . 7}$ & $\mathbf{7 3 9 3 . 0}$ \\
\hline
\end{tabular}

Figure 2. (A) Picture of the culture plate for MMT breast cancer cells treated with tamoxifen at increasing concentration, from left to right. Fluorescence measurements were made with a microplate reader with excitation at $480 \pm 10 \mathrm{~nm}$ and emission detection at $520 \pm 12.5 \mathrm{~nm}$. This figure shows fluorescence intensity decreasing as the concentration of tamoxifen increases. (B) Readings from one high school student's plate (not related to A). Note that the student did not put media in the second column, and he was not sure what he did for the final column. Learning to take comprehensive laboratory notes is part of the training and one reason students pool their data for the final plots. 
A.

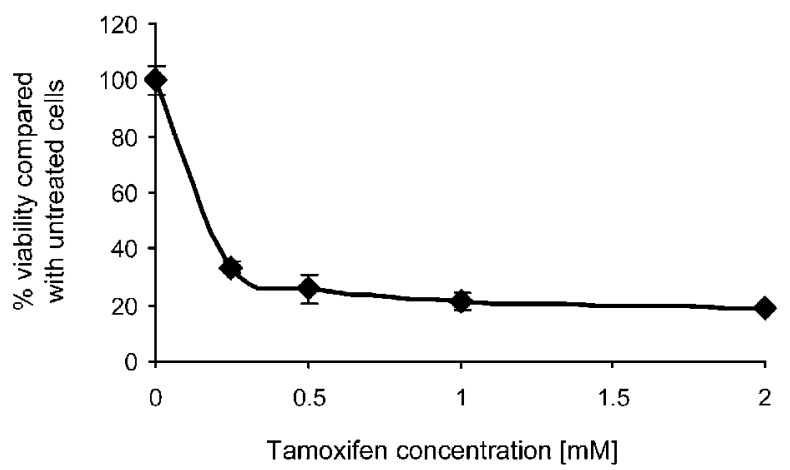

B.

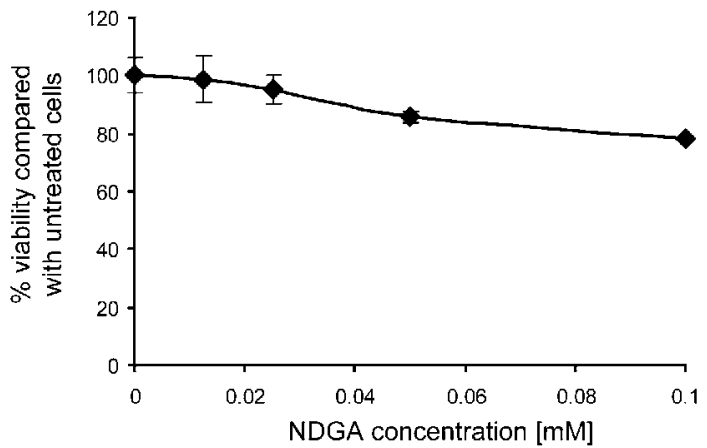

C.

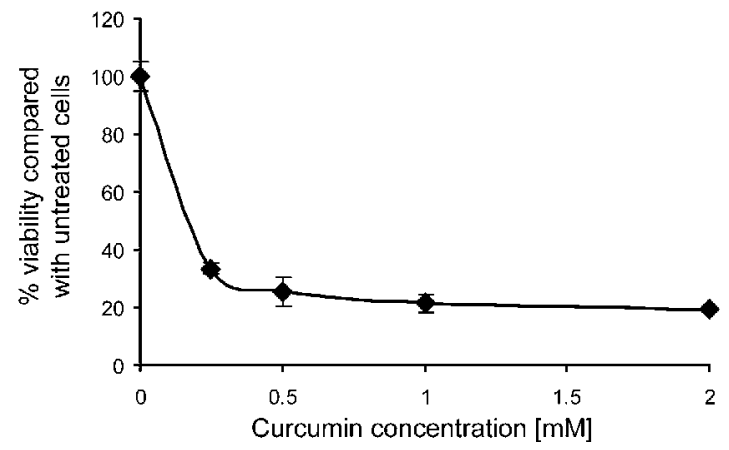

Figure 3. Concentration-dependent effects of (A) the antiestrogen tamoxifen $(n=16)$ on proliferation of MMT cells. (B) The LOX inhibitor NDGA $(n=21)$, and (C) the ornithine decarboxylase inhibitor curcumin $(n=15)$ after $48 \mathrm{~h}$. Results are expressed as a percentage of control, as compiled from separate trials done by high school students.

The NDGA results are consistent with the mixed endorsement of the plant derivative as a dependable supplement to current breast cancer treatments. Oncologists remain hesitant to recommend the high doses of NDGA that would be needed to obtain the results of alternative treatments because of its hepatotoxic effects (Lambert and Zhao, 2002).

Curcumin-treated MMT samples exhibited concentrationdependent inhibition of unregulated cellular growth. The drug's antiproliferative ability caused a significant inhibition of cell growth of more than $80 \%$ in the treated samples compared with the untreated control (Figure 3C).

The combination of tamoxifen and curcumin proved to be less effective than the use of tamoxifen or curcumin
A.

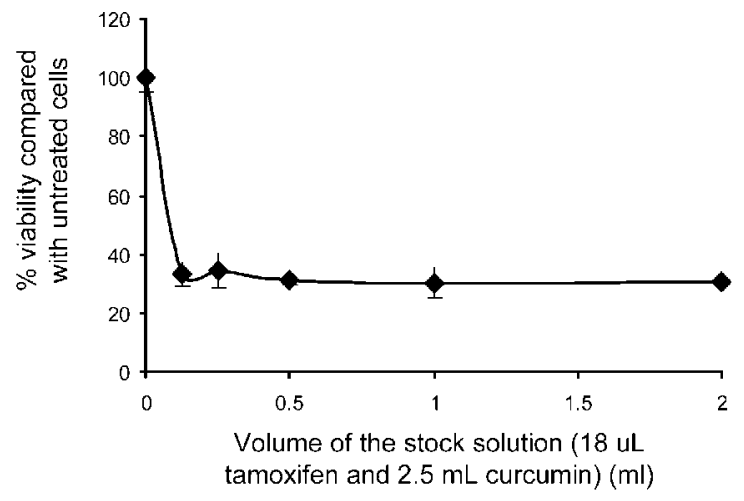

B.

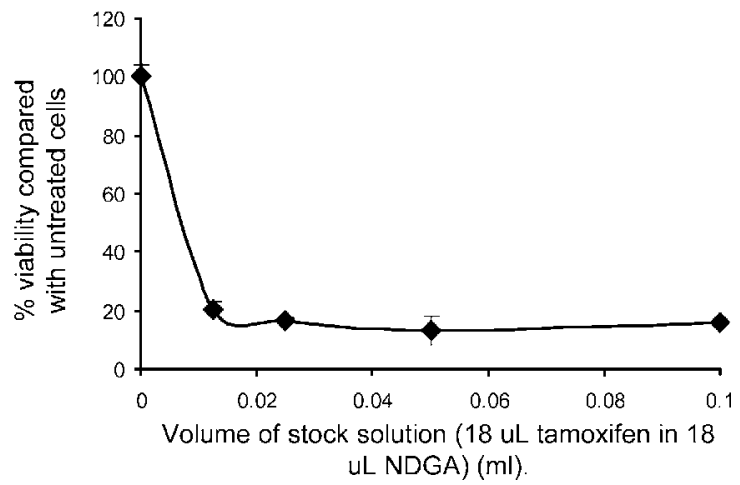

Figure 4. Concentration-dependent effects of (A) combination of tamoxifen and curcumin $(n=22)$ and (B) combination of tamoxifen and NDGA $(n=13)$ on proliferation of MMT cells after $48 \mathrm{~h}$. See Appendix $C$ for concentrations of stock solutions. Results are expressed as a percentage of control, as compiled from separate trials done by high school students.

individually. The extent of inhibition of cell proliferation by the combination of tamoxifen and curcumin was less than the inhibition observed in cells treated with tamoxifen alone (Figure 4A). The tamoxifen and NDGA drug combination proved to be more effective. Dose-response showed significant inhibition in proliferation compared with the control population (Figure 4B).

\section{ASSESSMENT WITHIN A RESEARCH SETTING}

The breast cancer antiproliferative assay is one of several ongoing experiments that students complete during a Walter Reed internship. Students who participate in this investigation, as well as those who do not, complete additional studies in immunology, high-throughput cloning, neurotoxicity assays, physiological challenges, engineering problems, and so forth. These experiments, although varied, provide a unified experience for the students because each is built upon a fundamental concept, an accessible question, common protocols, data collection and graphing, mathematical analysis, and the formation of conclusions. Students become part of the training laboratory and do not receive class credit, grades, or content exams. Therefore, the assessment instruments target the internship experience as a whole, with an emphasis on the opportunity to observe, 
think, extrapolate, validate, and skillfully conduct experiments. Furthermore, it is the students, not the senior researchers, who assess both the instructional experiments as well as the learning experience. Assessment thus becomes a process that is embedded in continuous input and culminates in a laboratory report or technical proficiency.

The following data are summarized from an external evaluation completed for the National Institutes of HealthScience and Education Partnership Award grant that funds this unique precollege/undergraduate research internship.

\section{Student Assessment of the Research Experience}

Precollege. Over the past $5 \mathrm{yr}, 498$ of the program's 735 students have come from a traditionally defined minority population, and female participation is consistently at $50 \%$ to $56 \%$. These data, which mirror regional public school demographics, would indicate that gender and racial/ethnic inequality is minimal within the precollege program. Although the mammalian cancer assay was originally conceived to "grab attention" in light of the high breast cancer mortality rates within minority communities, our experience has demonstrated that scientific investigations consistently engage participants when targeted to any adolescent interest.

All students are treated like laboratory investigators, in that the more-focused students move more quickly to the next experiment and less-skilled students are given every opportunity to try again. As indicated in Figure 5, doing research science, regardless of the specific discipline, has measurable effects on student attitudes. The antiproliferative cancer assay requires a student to remain involved with the experiment for a week. This commitment to a single concept, combined with daily assessments of cell viability, allows students to assume responsibility for their own learning. Tools and techniques become the framework for critical thinking and the construction of explanations. Through peerto-peer critiques, their skills are spotlighted and applauded.

As one part of an extensive pre-/post-2003 attitude survey, students were given seven questions that focused on whether

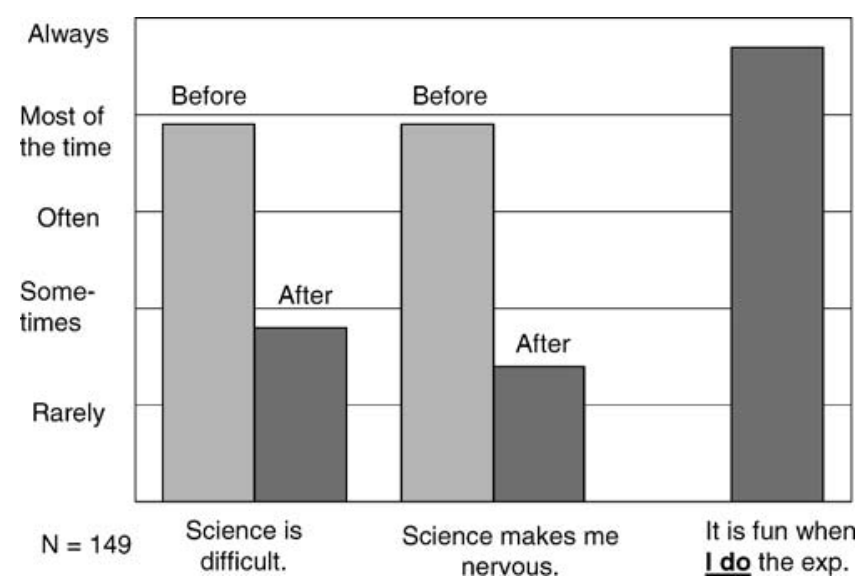

Figure 5. Student assessment of laboratory experiments, including the mammary cancer antiproliferation experiment. The 149 students took the same survey at the beginning and end of $1 \mathrm{wk}$ of laboratory training. The survey used a Likert scale ranging from 1 (rarely) to 5 (always). This figure illustrates the effect that doing authentic experiments has on middle/secondary school students' attitudes toward science and research. they liked "doing" or "listening" or "watching." "Doing an experiment" with only a protocol was the overwhelming favorite, as seen in column three of Figure 5.

Although the above data demonstrate that the students obviously enjoyed a research internship, the question of their continued interest in the sciences can only be implied. Our program has expanded from six students to 216 students over 5 yr (waiting lists excluded). Currently, 100\% of our senior students continue their education (20 seniors/yr only), $100 \%$ of returning students have taken another mathematics and/or science course, approximately $40 \%$ of our high school students participated in a science fair/building competition, and approximately $25 \%$ of the high school students returned for another year or more. Because of funding limitations, we can only anecdotally report that many students not returning to our program do attend a different summer internship. Furthermore, because the facility is not an accredited educational institution, legal barriers prohibit longer term data collection on minors.

Undergraduate. The breast cancer model has become a training tool for most undergraduates throughout the facility. During the external evaluation, 26 undergraduate researchers who had also participated in the precollege internships and the breast cancer investigation were asked to complete an eight-page postexperience survey.

These 26 undergraduate interns reported a high level of satisfaction with their internship experiences. Figure 6 provides a snapshot of their assessment. In the areas of skills acquisition, motivation, commitment, communications, leadership, and mentoring, the undergraduates felt that they had made significant progress toward their research and professional goals. These same 26 undergraduates were also mentors for the precollege students. In an effort to assess the undergraduate mentoring skills, the evaluator asked more than 200 precollege interns how they rated their undergraduate mentors. The final column of Figure 6 rates them as "awesome" (quote from a written response). The

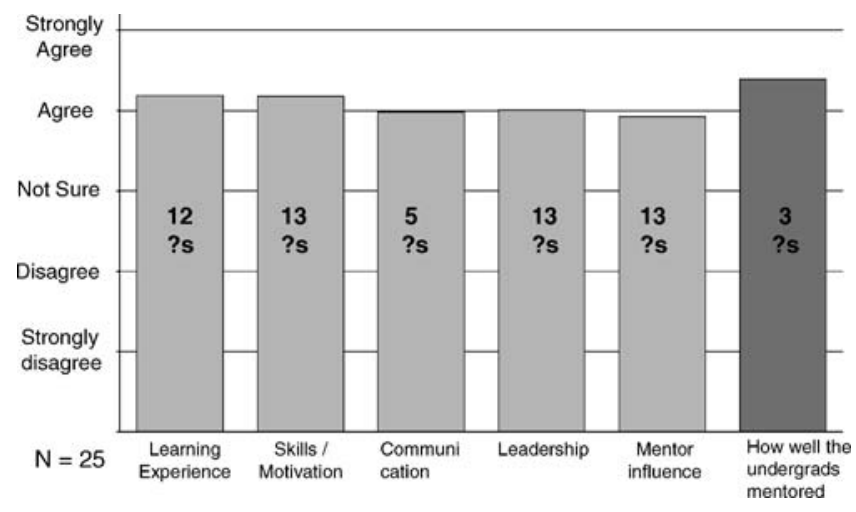

Figure 6. Undergraduate assessment of the effect of laboratory experiments used in training, including the breast cancer investigation. Various aspects of the internship experience were evaluated through clusters of questions. The numbers in the center of the bars represent the number of questions used to assess that particular cluster. 
breast cancer investigation illustrates the dominant pedagogical methodology at the WRAIR: the more-experienced person mentors the less-experienced person in a continuous hierarchy on the basis of knowledge-supplementing skills and skills applied in a knowledgeable manner to the question.

A similar undergraduate survey was administered in a pre- and postformat to all undergraduate interns $(n=82)$ in 2003. A preliminary analysis indicates that Figure 6 reflects the undergraduates' feelings across the facility. Given current retention and dismissal rates within the facility, we estimate that $98 \%$ of the undergraduate interns are prepared for further responsibilities within a week. A facility-wide review showed that $38 \%$ of all our undergraduate interns originate in a traditional minority population. This suggests that many of our high school students advance to undergraduate work at the facility and that minority students regard the WRAIR as a known internship opportunity. In addition, $43 \%$ of our undergraduates return for an additional year or more of internship.

Formative Evaluation. At the precollege level, an anonymous 2004 evaluation showed that high school students, age 15-18 yr, generally found the technical difficulty of the breast cancer experiments to be appropriate. Students were also asked to rate their interest in the individual protocols on a Likert-type scale from 1 (not interesting) to 5 (very interesting). Cell culture and maintenance and the introduction to breast cancer research scored $4.3 \pm 0.6$, cell plating and the drug assay scored $4.1 \pm 0.6$, and analysis of the drugs and discussion of their nature scored $4.1 \pm 0.5$. Students often announce that plating cells is boring and drawing plots is hard. Yet many of these same students ask to return to test herbal remedies. They had experienced the process of cell biology and had become excited about discovery.

Every student who has ever participated in the antiproliferative drug assay has obtained results that could be displayed and then analyzed. The sense of accomplishment that a student gains from conducting "my own research" solidifies their learning in advanced topics such as apoptotic pathways or the genetic basis behind deregulated protein cascades. At the same time, the students' active involvement in protocol design and data gathering shifts the stress of learning from rote memorization to memorable initiative taking.

\section{DISCUSSION}

The rodent breast cancer cell experiment asks and answers one facet of a simple question: What have recent advances in genetics brought to the standard regimens used in treating breast cancers? In $5 \mathrm{~d}$, in two 96-well plates, with readily available drugs, and at little more than the cost of media and cells, the student learns a range of laboratory skills and achieves competency in an adaptable yet common investigative assay. By focusing student attention on current pharmacological endeavors, the breast cancer study brings a relevant case study to the educational setting. The young researchers are excited, motivated, and frequently personally involved in the topic of cancer. Not only do students love the idea of working with an actual cancer model, they feel respected when given ownership of living cells and their fate.
The breast cancer experiment, as well as others designed by WRAIR scientists, follows a compromise approach between the "cookbook laboratory" and the "individually conceived science project." With our program, we learned early that "hands-on" is not enough to guarantee student learning. We noted that although students could be taught to manipulate equipment during an experiment, they could not necessarily apply their skills to a different project. These anecdotal observations, as reported by the scientists who helped launch the program, led to a change in the experimental emphasis from a hands-on to an inquiry method. As stated by both the American Association for the Advancement of Science (AAAS) and National Research Council (NRC) "inquiry is a set of interrelated processes by which scientists and students pose questions about the natural world and investigate phenomena; in doing so, students acquire knowledge and develop a rich understanding of concepts, principles, models and theories" (AAAS, 1993; NRC, 1995). The breast cancer experiment was one of the first investigations to diminish focus on technique to enhance the focus on concepts.

For the breast cancer cell training exercise, robust cells were selected to compensate for inexperience. Appendices became flexible so that more less-experienced students did less of the cell culture work and more-experienced students continued to maintain their own flasks. The structured daily protocols were refined, whereas the open-ended nature of the results was expanded and the initial emphasis on drug chemistry was replaced with the excitement of an unknown. These changes were quickly adopted by scientists at the WRAIR, who consistently work with students ranging from 16-yr-olds to fourth-year undergraduates. In fact, our investigators have revitalized their laboratory instruction by employing an inquiry emphasis on the breast cancer investigation and similar experiments (Shupp et al., 2005). In the breast cancer study, their generalized knowledge base is placed in context and made relevant through the experience of personally witnessing the life and death of cells. Initially students are hesitant to begin an experiment that does not include an answer key. In point of fact, the older, more academically polished student usually experiences the greatest difficulty when handed the protocol. The instructor must be patient with the pleas of "What do you want me to do?" and "What if I mess up and do it wrong?" and an investigator's personal favorite, "What is the answer?" However, by the end of the second day, most of the students are completely engaged with their project and become offended if another intern/instructor intervenes without express permission.

The WRAIR, a premier research and training facility, has developed a student internship model and experiments that can be duplicated in any private or public research laboratory. From the research scientist's viewpoint, the learning objectives are straightforward: Can the intern assume independent responsibility for an experiment that integrates basic cell biology techniques with producing reproducible laboratory notes and a standard experimental summary? Using integrated, independent projects such as the breast cancer investigation, the senior scientist can assess the student's research acumen, initiative, and ability to work with the laboratory team. 


\section{ACKNOWLEDGMENTS}

We thank the many mentors at WRAIR for their willingness to nurture a new generation of scientific researchers. We also thank the many undergraduate researchers who have taught this lesson to high school students in the GEMS program.

We thank the students and teachers at the Thomas Jefferson High School for Science and Technology in Fairfax, VA, and the McKinley Technical High School, District of Columbia Public Schools, for their support.

This work was funded by National Institutes of Health, Science and Education Partnership Award: Broadening of a Basic Race and Gender Equity Program, Phase 1; 5R25RR15629-01, Phase II; 1R25RR018619-01.

\section{REFERENCES}

Anonymous (1999). CyQUANT Cell Proliferation Assay Kit Product Information. Eugene, OR: Molecular Probes, 5.

American Association for the Advancement of Science (1993). Benchmarks for Science Literacy: Project 2061. New York: Oxford University Press.

Chagpar, A.B. (2004). Advances in the management of localized breast cancer: an overview. J. Ky. Med. Assoc. 102(5), 202-208.

Evan, G.I., and Vousden, K.H. (2001). Proliferation, cell cycle and apoptosis in cancer. Nature 411(6835), 342-348.

Grandishar, W.J. (2004). Tamoxifen-what next? Oncologist 9(4), 378-384.

Imaginis: The Breast Health Resource (2005). http://imaginis.com/ breasthealth/statistics.asp (accessed 27 March 2005).

Krzystyniak, K.L. (2002). Current strategies for anticancer chemoprevention and chemoprotection. Acta Pol. Pharm. 59(6), 473-478.

Lambert, J.D., and Zhao, D. (2002). Nordihydroguaiaretic acid: hepatotoxicity and detoxification in the mouse. Toxicon 40(12), 1701-1708.
Lou, Z., and Chen, J. (2003). BRCA proteins and DNA damage checkpoints. Front. Biosci. 1(8), s718-721.

McDonald, R.W., and Bunjobpon, W. (2001). Synthesis and anticancer activity of nordihydroguaiaretic acid (NDGA) and analogues. Anti-Cancer Drug Des. 16(6), 261-270.

McGuffin, M., and Hobbs, C. (1997). American Herbal Products Association's Botanical Safety Handbook. Boca Raton, FL: CRC Press.

Mehta, K., and Pantazis, F. (1997). Antiproliferative effect of curcumin (diferuloymethane) against human breast tumor cell lines. Anticancer Drugs 8(5), 470-481.

National Research Council (1995). National Science Education Standards. Washington, DC.: National Academy Press, 214.

Radice, P. (2002). Mutations of BRCA genes in hereditary breast and ovarian cancer. J. Exp. Clin. Cancer Res. 21(3 Suppl), 9-12.

Sheikh, N.M., and Philen, P.M. (1997). Chaparral-associated hepatotoxicity. Arch. Intern. Med. 157(8), 913-919.

Shupp, J., Yourick, D., Jett, M., and Anderson, M.K. (2005). Cell wars: a laboratory model for macrophage phagocytosis of gramnegative bacteria. American Society of Microbiology. http:// www.microlibrary.org (posted 2 January 2005 and accessed 27 March 2005).

Strauss, E. (1999). Pretesting tumors. Sci. Am. 280(2), 19-23.

Teh, S.H., and Hill, A.K. (2004). COX inhibitors modulate bFGFinduced cell survival in MCF-7 breast cancer cells. J Cell Biochem. 91(4), 796-807.

Tong, W., and Ding, X. (2002). Lipoxygenase inhibitors attenuate growth of human pancreatic cancer xenographs and induce apoptosis through the mitochondrial pathway. Mol. Cancer Ther. 1(11), 929-935.

Wallace, J.M. (2002). Nutritional and botanical modulation of the inflammatory cascade-eicosanoids, cyclooxygenases, and lipoxygenases-as an adjunct in cancer therapy. Integr. Cancer Ther. 1(1), 7-37. 


\section{Appendix A}

\section{MOUSE MAMMARY TUMOR CELL CULTURE AND MAINTENANCE}

Mouse mammary tumor (MMT) cells are obtained from American Type Culture collection (ATCC, Manassas, VA). The cell Line Designation is: MMT 060562/Catalog No. CCL51; mouse mammary gland tumor, epithelial morphology. Biosafety Level: 1.

\section{Preparation of Media}

The cells are grown in Eagle's Minimal Essential medium (EMEM) with Earle's BSS and $2 \mathrm{mM}$ L-glutamine that is modified by ATCC to contain $1.0 \mathrm{mM}$ sodium pyruvate, $0.1 \mathrm{mM}$ nonessential amino acids, and $1.5 \mathrm{~g} / \mathrm{L}$ sodium bicarbonate.

Before use, filter EMEM through a $0.2-\mu \mathrm{m}$ filter unit and supplement with $50 \mathrm{~mL}$ of $10 \%$ fetal bovine serum and $5 \mathrm{~mL}$ of Pen-Strep (10,000 units/mL penicillin and $100 \mu \mathrm{g} / \mathrm{mL}$ streptomycin)

\section{Handling Procedure for Frozen Cells}

All steps should be carried out in a sterile biological hood. Upon receipt of the culture, the cells should be thawed rapidly and initiated to maintain the highest level of viability. If continued storage is necessary, the frozen culture should be stored in liquid nitrogen vapor phase.

1. Thaw the vial rapidly (within $2 \mathrm{~min}$ ) by gentle agitation in a $37^{\circ} \mathrm{C}$ water bath.

2. Remove from the water bath and decontaminate the vial with $70 \%$ ethanol. All protocols should be followed under strict aseptic technique from this point on.

3. Prepare a $25-\mathrm{cm}^{2}$ tissue culture flask. Under strict aseptic technique, add approximately $5 \mathrm{ml}$ of prepared medium. Because it is important to avoid excessive alkalinity of the medium during the cell recovery stage, place the culture flask containing the medium in the incubator for $15 \mathrm{~min}$ before adding the cells. This allows the medium to reach its normal $\mathrm{pH}$ of 7.0-7.6.

4. Transfer the vial contents to the $25-\mathrm{cm}^{2}$ tissue culture flask.

5. Incubate the culture at $37^{\circ} \mathrm{C}$ in a humidified $5 \% \mathrm{CO}_{2}$ atmosphere until a confluent monolayer is observed under a microscope (generally within $24 \mathrm{~h}$ ).

\section{Media Renewal}

Media renewal should be done two to three times weekly. Media should be checked for:

- Clarity. The presence of debris or cloudiness is due to detached cells. This often occurs if the culture has grown so much that it can no longer maintain a confluent monolayer.

- Color. Cell medium is often supplemented with a $\mathrm{pH}$ indicator. Upon arrival, the bright red color of the medium indicates a neutral $\mathrm{pH}$. Over the course of the week, the medium will progress from red to orange to yellow as a sign of increasing acidity.

\section{Subculturing Procedure for Flask Cultures}

Because these cells grow rapidly, it is recommended that subculture be done two times weekly at a ratio of 1:2. All volumes used in the following protocol are for a $75-\mathrm{cm}^{2}$ tissue culture flask and can be reduced or augmented as necessary.

1. Warm prepared cell media and trypsin in a $37^{\circ} \mathrm{C}$ water bath.

2. Wipe down the hood and all items inside with $70 \%$ ethanol.

3. If available, sterilize the bio-safety hood by turning on the ultraviolet light for 5-10 min.

4. Remove $25-\mathrm{cm}^{2}$ flasks containing the cell culture from the incubator.

5. Confirm cell confluence with an inverted microscope. Look for any possibility of contamination and evaluate the health of the cells.

6. Sterilize the outside of cell containers and your gloved hands with $70 \%$ ethanol, and place the flasks in the hood.

7. Use a pipette to remove the media from each flask and discard into waste beaker.

8. Pipette $15 \mathrm{~mL}$ of filtered phosphate-buffered saline (PBS) into each flask and wash the cells by holding the flask horizontally and slowly tipping it from side to side for about $30 \mathrm{~s}$.

9. Remove PBS by pouring it into a waste beaker. Repeat steps 7 and 8 one more time.

10. Pipette $3 \mathrm{~mL}$ of trypsin-EDTA solution into each flask and expose the cells by holding the flask horizontally and slowly tipping it from side to side.

11. Let the flasks sit horizontally in the hood $(\sim 10 \mathrm{~min})$ or back in the incubator $(\sim 5 \mathrm{~min})$ until the trypsin begins to look cloudy.

12. Pipette $5 \mathrm{~mL}$ of medium into each flask to neutralize the trypsin.

13. Centrifuge at $3,000 \mathrm{rpm}$ for $10 \mathrm{~min}$. Resuspend the pellets in $10 \mathrm{~mL}$ of fresh sterile medium.

14. Incubate the cells in a 75-cm flask(s) in the incubator at $37^{\circ} \mathrm{C}$ in a humidified $5 \% \mathrm{CO}_{2}$ atmosphere.

\section{Appendix B}

\section{PREPARATION OF STUDENT CELL CULTURE}

On day 1, students receive their own aliquot of mouse mammary tumor (MMT) cells at a known concentration. Because the number of cells that goes into each well of a 96well plate during the day 1 plating procedure must be constant, the concentration of the isolated cells must be obtained and modified before plating.

\section{Cell Culture Detachment}

Follow steps 1-11 of "Subculturing Procedure for Flask Cultures" in Appendix A for four flasks of MMT cells grown to a confluent monolayer.

Obtain two 50-mL tubes and divide the mixture of cells and trypsin-EDTA solution from each flask into the two tubes.

Balance the 50-mL tubes in a centrifuge and set the speed at $1,200-1,500 \mathrm{rpm}$ and a temperature of $4^{\circ} \mathrm{C}$ for a period of $5 \mathrm{~min}$.

Remove the tubes and look for a small white pellet of cells in the bottom. (If a pellet has not formed, continue to centrifuge the cells for an additional $5 \mathrm{~min}$ at the same settings.) Very gently pour off the supernatant, making certain the pellet stays in place.

Pipette $3 \mathrm{~mL}$ of medium into each tube and mix by gently pipetting. Combine suspended cells from both tubes into one tube. 
Rinse the empty tube with $1 \mathrm{~mL}$ of medium; add this volume to the tube containing the suspended cells and vortex briefly.

Pipette $10 \mu \mathrm{L}$ of suspended cells into a $1.5-\mathrm{mL}$ tube. Add $90 \mu \mathrm{L}$ of prepared trypan blue dye $(0.4 \%$ trypan blue dye and sterile distilled water in 1:25 dilution). Vortex at a low speed.

The instructor calculates the cell concentration with a hemocytometer (see Appendix D, Day 3, for student review). Using the cell concentration worksheet (answer key below) ensure that there are $5 \times 10^{4}$ cells/mL for plating. If there are insufficient cells, the instructor should perform trypsinization on additional flasks or alter the number of cells that should be present in each well of the 96-well plate. The total amount of cell suspension required will depend upon the size of the class.

\section{Cell Concentration Worksheet (Solution)}

We want a concentration of 10,000 cells suspended in $200 \mu \mathrm{L}$ of medium in each well of a 96-well plate. Find the concentration of cells per milliliter that is in each well. Show calculations below. (Hint: $1 \mathrm{~mL}=1,000 \mu \mathrm{L}$ )

$$
(10,000 \text { cells }) /(0.2 \mathrm{~mL})=5 \times 10^{4} \text { cells } / \mathrm{mL}
$$

Desired cell concentration (cells $/ \mathrm{mL})=5 \times 10^{4}$ cells $/ \mathrm{mL}$

From the hemocytometer, a device used to measure the concentration of cells in a cell-medium suspension, the researcher obtains two cell counts.

$$
\begin{aligned}
& \text { Cell count } \# 1=36 \text { cells } \\
& \text { Cell count } \# 2=30 \text { cells }
\end{aligned}
$$

Find the average cell count.

$$
\text { Average cell count }=\underline{(36+30) / 2}=\underline{33 \text { cells }}
$$

The average cell count will allow us to calculate the concentration of cells in our cell-medium suspension. Earlier, we had done a 10:1 dilution with trypan blue dye, the dye that allows us to visualize cells on our hemocytometer. Therefore, we must now multiply the average cell count by 10 .

$$
\text { (Average cell count) } \times 10=\underline{330}
$$

Multiply this number by $10^{4}$ cells $/ \mathrm{mL}$. This gives the concentration of cells in medium that we currently have.

$$
\text { Current cell concentration }=\underline{330 \times 10^{4} \text { cells } / \mathrm{mL}}
$$

We have $6 \mathrm{~mL}$ of cell-medium suspension in our container. Multiply the concentration by $6 \mathrm{~mL}$ to obtain the total number of cells in the container.

$$
\text { Total cells }=\underline{1.98 \times 10^{7} \text { cells }}
$$

Remember from step 1 that we want to obtain a final cell concentration of $5 \times 10^{4}$ cells $/ \mathrm{mL}$ from our current cell concentration of $330 \times 10^{4}$ cells $/ \mathrm{mL}$. To do so, we must add medium to our $6 \mathrm{~mL}$ of cells to dilute to the desired concentration. Find the amount of medium we must add.

$$
\begin{gathered}
\text { (Total cells/desired concentration) }-(6 \mathrm{~mL}) \\
=\underline{390 \mathrm{~mL} \text { of medium }}
\end{gathered}
$$

However, we might not need nearly this amount of cell suspension. Say, for example, that $120 \mathrm{~mL}$ of cell suspension is all that is needed.

That could be obtained by taking $2 \mathrm{~mL}$ of cell suspension and adding $130 \mathrm{~mL}$ of medium.

\section{Appendix C \\ DRUG STOCKS AND DILUTIONS}

This appendix is designed for instructor or research assistant use only. Volumes can be augmented or reduced depending on the size of the class taught or the number of plates desired per student. Each weeklong experiment involves the use of the following five "unknown" drugs. The stock solutions for each drug are prepared according to the concentrations listed below and are thoroughly mixed before use to dissolve all solids. Tables 1-5 provide the concentrations to which the stock solutions will be diluted with EMEM medium. These concentrations can also be adjusted to provide more refined concentration curves. Refer to student handouts (Appendix D) for specific dilutions protocol.

Other drugs, such as 5-fluorouracil, can also be used effectively. Our facility has also tested simple pharmacological agents such as aspirin, hydrogen peroxide, antibiotics, and

Table 1. Curcumin stock solution: $10 \mathrm{mg} / \mathrm{mL}$ in 200-proof ethanol

\begin{tabular}{crc}
\hline Concentration $(\mathrm{mM})$ & Medium & Stock solution \\
\hline & & \\
0.25 & 1,500 & 100 \\
0.5 & 1,400 & 200 \\
1 & 1,200 & 400 \\
2 & 800 & 800 \\
\hline
\end{tabular}

Table 2. Nordihydroguaiaretic acid (NDGA) stock solution: $15 \mathrm{mg} /$ $\mathrm{mL}$ in 200-proof ethanol

\begin{tabular}{lcc}
\hline Concentration $(\mathrm{mM})$ & Medium & Stock solution \\
\hline 0.0125 & $1,599.6$ & 0.4 \\
0.025 & $1,599.2$ & 0.8 \\
0.05 & $1,598.4$ & 1.6 \\
0.1 & $1,596.8$ & 3.2 \\
\hline
\end{tabular}

Table 3. Tamoxifen stock solution: $250 \mathrm{mg} / \mathrm{mL}$ in dimethyl sulfoxide

\begin{tabular}{ccc}
\hline Concentration $(\mathrm{mM})$ & Medium & Stock solution \\
\hline 0.005 & $1,599.6$ & 0.4 \\
0.01 & $1,599.2$ & 0.8 \\
0.02 & $1,598.4$ & 1.6 \\
0.04 & $1,596.8$ & 3.2 \\
\hline
\end{tabular}

Table 4. Tamoxifen and curcumin stock solution: $18-\mu \mathrm{L}$ tamoxifen stock solution $(250 \mathrm{mg} / \mathrm{mL}$ in dimethyl sulfoxide) in $2.5-\mathrm{mL}$ curcumin stock solution (10 mg/mL in 200-proof ethanol)

\begin{tabular}{rc}
\hline Medium & Stock solution \\
\hline $1,499.6$ & 100.4 \\
$1,399.2$ & 200.8 \\
$1,198.4$ & 401.6 \\
796.8 & 803.2 \\
\hline
\end{tabular}


Table 5. Tamoxifen and NDGA stock solution: $18-\mu \mathrm{L}$ tamoxifen stock solution in $18-\mu \mathrm{L}$ NDGA stock solution

\begin{tabular}{cc}
\hline Medium & Stock solution \\
\hline & \\
$1,599.2$ & 0.8 \\
$1,598.4$ & 1.6 \\
$1,596.8$ & 3.2 \\
$1,593.6$ & 6.4 \\
\hline
\end{tabular}

various herbs to give the students an opportunity to design "their own" study.

\section{Appendix D Student Guide}

\section{DAY 1}

\section{Introduction, Cell Concentration Calculations, and Plating Cells}

\section{Materials}

Student handouts

Two 96-well plates/student or team

150-mL tube containing known concentration of MMT cells

1 15-mL tube containing sterile distilled water

Several repeaters

Bicomb Eppendorf tips for the repeater $(1=100 \mu \mathrm{L})$

Personal protective equipment (PPE): lab coat, goggles, gloves

Demonstration plate

\section{Procedure}

Background information on breast cancer and any applicable review.

Plating Cells: Students will plate their own cells. This protocol should be carried out under sterile conditions either on a clean bench or in a bio-safety hood. The students and instructor must wear gloves, lab coat, and goggles.

As an example for the class, the instructor should have a properly labeled demonstration plate on the bench.

\section{Cell Plating}

Take one 96-well plate into the sterilized hood. Open the packaging, being careful not to take the lid off of the plate.

1. Label the plates in small writing at the top with your names, the date, and name of the cell line. Also write initials on the side of the plate, while being careful not to jostle the lid on the plate. Draw a line over the very outer group of wells. These will be filled with sterile distilled water (evaporation of fluid from these outer wells makes the data from them undependable, so we simply add water to them).

2. Remove the lid and place it face up in the hood.

3. Place a tip into the Eppendorf repeater, being careful not to touch the tip and making sure that the tip locks into place.

4. Dispense $100 \mu \mathrm{L}$ of distilled water per well to fill the outer wells.

5. Discard this tip into a sharps container.
6. Gently mix the cells by inverting the $50-\mathrm{mL}$ tube several times. The aliquoted cell culture is provided by the instructor and labeled MMT.

7. Use a new tip to fill the inner 60 wells with $200 \mu \mathrm{L}$ of cells in medium. On occasion, recap the tube and invert. If the cells are allowed to sit undisturbed, they tend to settle to the bottom, changing the cell concentration. Use a fresh tip when you are ready to continue pipetting.

8. When finished, discard the tip and place the lid back on the plate.

9. Repeat these steps for the second plate if necessary.

10. After all wells are filled, place them back into the incubator. The two plates can be stacked.

11. Clean your area with ethanol when finished.

Cells are incubated until $\sim 70 \%$ confluence, usually $24 \mathrm{~h}$ (Figure 1).

\section{DAY 2}

\section{Introduction to Drug Dilutions and Performing a Cellular Drug Resistance Assay}

\section{Materials}

Drug Assay Worksheets

2 1.5-mL tubes each containing an unknown drug or combination of drugs

1 15-mL tube containing modified EMEM cell media

124 -well plate

296-well plates containing confluent MMT cells (from day 1 )

$1,000,100$, and $10-\mu \mathrm{L}$ pipettes with tips

Several repeaters

Bicomb Eppendorf tips for the repeater $(1=50 \mu \mathrm{L})$

PPE: lab coat, goggles, gloves

Demonstration plate

\section{Procedure}

Cell Concentration Worksheet. Students and teacher complete the formula sheet to calculate the final cell/medium suspension required for the sample number provided by the instructor. This can be done in the classroom or at the bench.

Drug Assay Worksheet. Each student will receive two drugs from the instructor for each 96-well plate. Fill out the appropriate Drug Assay Worksheet for each drug. These worksheets will be used later today.

The instructor should have a demonstration plate that illustrates how to label the additional information on the 96-well plate.

Each person has received two vials of unknown drugs. We will now prepare several different dilutions of each of the two drugs on 24-well plates. These will later be added to our plated cells.

Place the appropriate drug dilution sheets close by so they can be easily read.

1. Sterilize the workspace with $70 \%$ ethanol.

2. Carefully open the 24-well plate and label it according to the drug dilution sheet. As shown, to the far left, write drug number and medium type and then write the appropriate amount of the dilution and medium for that well.

3. Begin making the drug dilution by adding the appropriate amount of medium to the first well of the first drug dilution. This amount is specified on the Drug Assay Worksheet. Make sure to use the appropriate size of pipette and a sterile pipette tip. 
4. Continue to add the appropriate amount of medium to the rest of the wells for the first drug's dilution. Dispose of the tip in the sharps bin.

5. Next, add the appropriate amount of the drug into the first and second wells of the plate. Dispose of this tip.

6. Mix the dilution in the first well by pipetting up and down several times with a new tip. Add the appropriate amount of this dilution to the third well. Dispose of this tip.

7. Take another new tip and mix the dilution in the second well by pipetting the solution up and down several times. Add the appropriate amount of this dilution to the fourth well.

This procedure can be repeated to make the second drug's dilution.

\section{Performing the Drug Assay or Plating the Dilutions}

1. The instructor will demonstrate this procedure for adding the drug dilutions to the 96-well plates, before the students do the same to their own plates. The Drug Assay Worksheet should be used as a reference. After the instructor is done, he or she will come around and check the students' Drug Assay Worksheets to make sure that they are properly filled in. Then the instructor will remove the students' plates from the incubator and distribute them so the students can begin the procedure. Remove the 96-well plates from the incubator and place on a sterilized surface.

2. There will be 10 columns of cells with four wells per column. For beginning students, use two columns for each dilution of the drug (eight replicates). For more experienced students, one column or four replicates is usually sufficient. Label each plate with the appropriate drug number (the number on your vial) and drug dilution number as shown on the Drug Assay Worksheet. A diagram of a labeled 96-well plate is shown on the worksheet.

3. Place a fresh sterile tip into a repeater. Set the dial so that $50 \mu \mathrm{L}$ will be dispensed with each click.

4. Take one plate aside and remove the lid, placing it face up in the clean/sterile work area.

5. Add $50 \mu \mathrm{L}$ of the first drug dilution to the first two columns of the cells.

6. Change the repeater tip and add $50 \mu \mathrm{L}$ of the second dilution to the third and fourth column of the cells.

7. Continue changing tips for each dilution and continue adding each dilution to the appropriate columns of cells.

8. There were four dilutions of each drug and five pairs of columns per drug. The fifth pair of columns is for medium to be added to the cells with no drug. This is the control set of wells.

9. Place the lid on the plate and place this plate aside in the incubator.

10. Repeat the procedure if necessary to the second 96-well plate.

When finished, place all plates back into the incubator. Clean up the area and wipe all surfaces down with $70 \%$ ethanol.

\section{DAY 3}

Your class will receive an aliquot of MMT cells of unknown cell concentration. Using a hemocytometer, you will calculate the cell concentration as well as the dilution required to achieve the required 10,000 cells suspended in $200 \mu \mathrm{L}$ of medium. Once the cells are diluted and concentration is confirmed, the cells can be returned to a tissue culture flask.

\section{Using a Hemocytometer to Estimate Cell Concentration}

Pipette $10 \mu \mathrm{L}$ of suspended cells into a 1.5-mL tube. Add $90 \mu \mathrm{L}$ of prepared trypan blue dye $(0.4 \%$ trypan blue dye and sterile distilled water in a 1:25 dilution). Vortex at a low speed.

Place a coverslip over the slide with the hemocytometer grid. Pipette $10 \mu \mathrm{L}$ of the cell/dye dilution into each side of the slide.

Focus the microscope on the hemocytometer grid and bring the upper left square of the large grid square into view.

Begin to count the cells found in this section of the hemocytometer grid. Record this number and move the slide to count the number of cells in the lower left corner, upper right corner, and lower right corner, recording the additional values as you continue.

Add the recorded values together and divide by four to get an average number of cells per square. This value will be known as cell count 1 .

Move the focus of the microscope to the second grid of the hemocytometer and repeat this method of counting to find a second average number of cells per square for the upper half of the instrument. This value will be known as cell count 2 .

\section{Cell Concentration Worksheet}

We want a concentration of 10,000 cells suspended in $200 \mu \mathrm{L}$ of medium in each well of a 96-well plate. Find the concentration of cells per milliliter that is in each well. Show calculations below. (Hint: $1 \mathrm{~mL}=1,000 \mu \mathrm{L}$ )

Desired cell concentration $($ cells $/ \mathrm{mL})=$

From the hemocytometer, a device used to measure the concentration of cells in a cell-medium suspension, the researcher obtains two cell counts.

$$
\begin{aligned}
& \text { Cell count } \# 1=36 \text { cells } \\
& \text { Cell count } \# 2=30 \text { cells }
\end{aligned}
$$

Find the average cell count.

Average cell count $=$

The average cell count will allow us to calculate the concentration of cells in our cell-medium suspension. Earlier, we had done a 10:1 dilution with trypan blue dye, the dye that allows us to visualize cells on our hemocytometer. Therefore, we must now multiply the average cell count by 10 .

(Average cell count) $\times 10=$

Multiply this number by $10^{4}$ cells/mL. This gives the concentration of cells in medium that we currently have.

\section{Current cell concentration $=$}

We have $6 \mathrm{~mL}$ of cell-medium suspension in our container. Multiply the concentration by $6 \mathrm{~mL}$ to obtain the total number of cells in the container. 
Total cells $=$

Remember from step 1 that we want to obtain a final cell concentration of concentration of from our current cell centration. Find the amount of medium we must add.

(Total cells/desired concentration $)-(6 \mathrm{~mL})$

\section{DAY 4}

Using data from the previous year or demonstration plates, you will learn how to read fluorescent scan spreadsheets and how to do a simple analysis. The breast cancer model has traditionally used CyQUANT because of its simplicity, but other proliferation assay kits would be just as effective. Your instructor will review the product literature to help you determine what is being measured. Your instructor will demonstrate how to use the scanner or plate reader to acquire and analyze the image. Also, the instructor will explain how to save the data in a tab-delimited format and use spreadsheet data analysis software (MS Excel, SigmaPlot) to plot the data and carry out some statistical analyses, such as averaging the data. Cell cultures may be frozen at this point.

\section{DAY 5}

\section{Cell Proliferation Assay, Scanning, and Analysis}

\section{Materials}

CyQuant Cell Proliferation Assay Kit (consists of components $\mathrm{A}$ and $\mathrm{B}$ )

2 96-well plates incubated with drug assay

$1,000-\mu \mathrm{L}$ pipette with tips

Eppendorf repeater with $100-\mu \mathrm{L}$ tips

150 -mL tube wrapped in aluminum foil

Sterile distilled water

Scanner, inverted microscope

\section{Procedure}

Part 1: Preparation for Scanning. Prepare the plates for scanning with the CyQuant Cell Proliferation Assay Kit.

1. Remove both 96-well plates from the incubator. Remove the lids and invert both plates onto an absorbent pad to remove all of the medium. Shake vigorously to ensure complete medium removal.

2. Stack plates right side up and place in the freezer for at least $30 \mathrm{~min}$ (overnight is fine).

3. Obtain a 50-mL tube and wrap in aluminum foil. This tube will contain the dye mixture.

4. Mix $2 \mathrm{~mL}$ of buffer stock (component B) with $38 \mathrm{~mL}$ of distilled water in the 50-mL tube.

5. Add $100 \mu \mathrm{L}$ of CyQuant GR stock solution (component A) to the tube. Vortex.

6. Using a repeater, add $200 \mu \mathrm{L}$ of your dye mixture to each sample well.

7. Incubate for 5-20 $\mathrm{min}$ at room temperature and minimal light exposure.

8. The plates are now ready to be scanned using the BioRad software. They will be read at $480 \mathrm{~nm}$ excitation and $520 \mathrm{~nm}$ emission. A low fluorescence reading specifies cell death, indicating a potential drug for treatment, whereas higher fluorescence specifies viable cells, indicating an ineffective drug or drug dosage against these cells.

Part 2: Analysis. Students learn how to export their data from the scanner and how to use a spreadsheet, analyze the data, and create plots. Each drug is added at increasing concentrations in four to eight wells for each concentration. Students calculate the average cell number for each concentration and divide it by the cell number in the control wells. This yields the percentage of viable cells for each treatment. The results are plotted and compared with standard curves that have been previously established by the instructor. Once the students have matched their plots to the standard, the names and nature of the drugs are revealed and discussed. The students then discuss effective drug or drug combination(s) on the basis of cell proliferation. 


\section{Appendix E}

Student drug assay worksheet: The worksheet serves as a student protocol as well as a teaching instrument. Students calculate the volume of drug stock needed to complete the table. The sheet varies for each drug. In this example, the student is given curcumin and NDGA.

\section{Drug Assay Worksheet}

Name

You have been given two small vials of unknown drugs \#1 and \#2. We want to dilute the drug stock with media so that there is a total of $1600 \mathrm{uL}$ in each well of the 24-well plate. With this information, complete the charts below.

\begin{tabular}{|c|c|c|c|c|}
\hline Druq & Final conc [mM] & Dilution & Media $(\boldsymbol{\mu L})$ & Druq Stock \\
\hline$\# 1$ & 0 & $\mathrm{C}$ & 1600 & \\
\hline & 0.25 & 1 & 1500 & \\
\hline & 0.50 & 2 & 1400 & \\
\hline & 1.00 & 3 & 1200 & \\
\hline & 2.00 & 4 & 800 & \\
\hline
\end{tabular}

\begin{tabular}{|c|c|c|c|c|}
\hline Druq & Final conc [mM] & Dilution & Media $(\boldsymbol{\mu L})$ & Druq Stock \\
\hline \#2 & 0 & $\mathrm{C}$ & 1600 & \\
\hline & 0.0125 & 1 & 1599.6 & \\
\hline & 0.0250 & 2 & 1599.2 & \\
\hline & 0.0500 & 3 & 1598.4 & \\
\hline & 0.1000 & 4 & 1596.8 & \\
\hline
\end{tabular}

Add the calculated amount of drug stock and the corresponding amount of media to each well of a 24-well plate according to the diagram shown below. Pipette up and down to ensure even mixing. The grayed-out wells should be left blank.

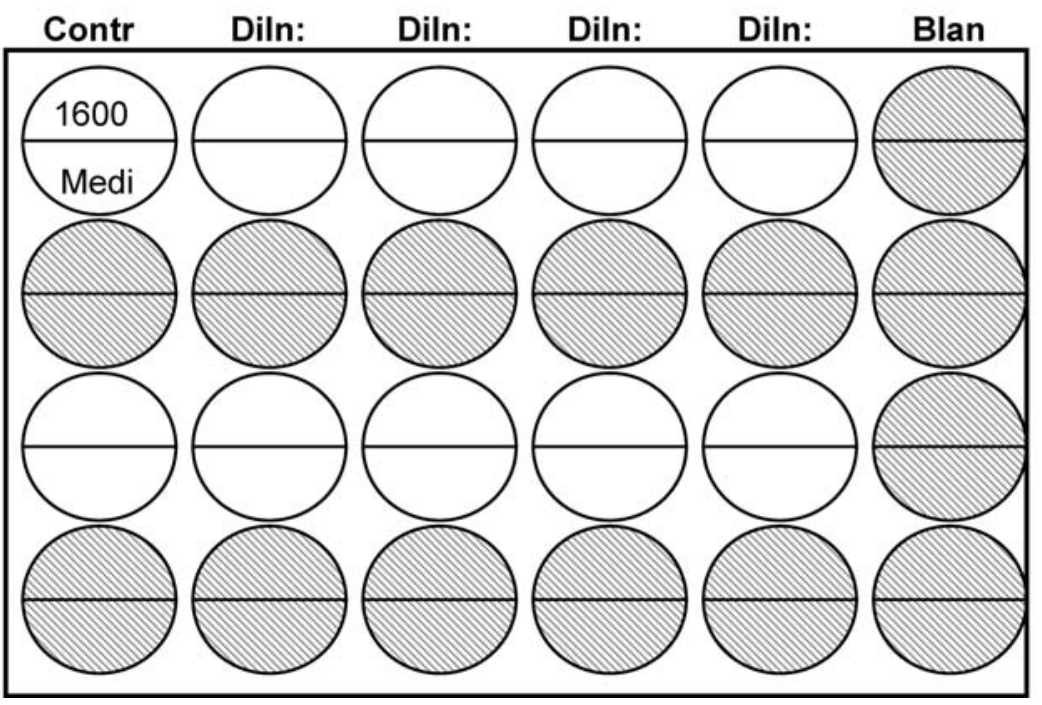

